\title{
Severe malaria in children in Yemen: two site observational study
}

\author{
Abdullah Al-Taiar, Shabbar Jaffar, Ali Assabri, Molham Al-Habori, Ahmed Azazy, Nagiba Al-Mahdi, Khaled Ameen, \\ Brian M Greenwood, Christopher J M Whitty
}

\begin{abstract}
Objectives To assess the burden of malaria on health services, describe the clinical presentation of severe malaria in children, and identify factors associated with mortality by means of a prospective observational study.

Setting Two public hospitals in Taiz (mountain hinterland) and Hodeidah (coastal plain), Yemen.

Participants Children aged 6 months to 10 years.

Results Of 12301 paediatric admissions, 2071 (17\%) were for suspected severe malaria. The proportion of such admissions varied according to the season (from 1\% to 40\%). Falciparum malaria was confirmed in 1332 children; 808 had severe disease as defined by the World Health Organization. Main presentations were respiratory distress $(322 / 808,40 \%)$, severe anaemia (291/800, 37\%), and cerebral malaria (60/808, 8\%). Twenty two of 26 children who died had a neurological presentation. No deaths occurred in children with severe anaemia but no other signs of severity. In multivariate analysis, a Blantyre coma score $\leq 2$, history of fits, female sex, and hyperlactataemia predicted mortality; severe anaemia, respiratory distress, and hyperparasitaemia were not significant predictors of mortality.

Conclusions Severe malaria puts a high burden on health services in Yemen. Although presentation is similar to African series, some important differences exist. Case fatality is higher in girls.
\end{abstract}

\section{Introduction}

As with many other health problems in the Middle East, little is known about patterns of clinical malaria. ${ }^{1}$ Malaria is not usually thought of as a major disease in this area and the pattern is often assumed to be similar to that seen in southern Asia, where most disease is in adults infected with Plasmodium vivax. However, data from the World Health Organization suggest that after Afghanistan, where vivax is the predominant species, Yemen has the highest incidence of malaria in the east Mediterranean region of WHO, and Plasmodium falciparum is responsible for a high proportion of reported cases. ${ }^{2}$

Most studies on severe malaria in children have been undertaken in sub-Saharan Africa, and its presentation varies with the intensity of malaria transmission. ${ }^{3-6}$ Severe malarial anaemia, which tends to affect younger children, is thought to be the dominant form of severe malaria in areas of high transmission, ${ }^{3-5}$ and cerebral malaria, which affects older children, more common in areas of low and seasonal malaria transmission. ${ }^{4}$ It is not clear whether this is due to immunity from repeated exposure or because the disease presents differently in older children.
Little is known of the pattern of malaria in Yemen, one of the most highly populated countries in the Middle East. The country has few resources relative to its neighbours and rural poverty is widespread. Health services are, however, more accessible than in most of Africa. Local mosquitoes (especially Anopheles arabiensis) are efficient vectors of malaria, and local farming practices, such as cultivation of the qat tree, may favour transmission. Even in parts of Yemen with the highest levels of transmission, transmission is much lower than in sites of previous studies of paediatric malaria in Africa, and immunity probably has less effect on the pattern of clinical infections. Climatic conditions vary across the country from the hot coastal plains, through a mountainous hinterland, to a semi-desert plateau. We carried out an observational study of the clinical pattern of malaria in two epidemiological settings: the coastal plain and the mountain hinterland. Malaria is not thought to be transmitted in the inland plateau.

We set out to determine the proportion of paediatric admissions in public hospitals that are due to severe malaria, to examine the presentation of severe malaria in a Middle Eastern context, and to explore the risk factors for death from malaria in this population. We cannot assume that lessons learnt in observational studies in Africa will apply to the different epidemiological, genetic, cultural, and healthcare settings of the Middle East in general, and Yemen in particular.

\section{Methods}

We conducted our study in Taiz-a densely populated province with a population of 2.4 million, which is typical of the mountainous hinterland-and in Hodeidah-a major city on the coastal plain. Focus group discussions and surveys in villages indicated that most or all children with severe febrile illness would visit hospital, either directly or on referral from primary care. We recruited study subjects from the Yemeni-Swedish Hospital, which provides most of the non-private paediatric beds in Taiz, and Althowra Hospital, the only public hospital that admits children in Hodeidah city. The hospitals are typical for the country and have paediatrician to bed ratios of about 1:5. Blood for transfusion is readily available, usually within an hour of request. We established identical surveillance systems for admission to the two hospitals for the duration of the study after joint training of research staff. Clinical research cover was provided for 24 hours a day, seven days a week during the study at both sites.

We consecutively recruited children if they had a positive blood film for asexual forms of $P$ falciparum; were between 6 months and 10 years old; required admission to hospital; and their parents gave written informed consent for their child to participate. Cases were defined as severe if they met current 
WHO criteria for severe malaria in children ${ }^{7}$; the box shows the definitions used for the symptoms and signs. A dedicated clinical research team used standardised methods to take a clinical history and perform a clinical examination. Laboratory results were fed back to clinical teams. Management was determined by the treating doctor without interference from research clinicians, except that study doctors gave all children with coma a bolus of $50 \%$ dextrose $(1 \mathrm{ml} / \mathrm{kg})$ diluted in isotonic fluid. Severe malaria is treated with parenteral quinine in Yemen, and at the time of our study first line treatment for non-severe disease was chloroquine.

Thick and thin blood films were prepared and stained with Giemsa; 100 high power fields were examined in a thick film before it was considered negative. Two laboratory technicians at each site independently read the blood films for malaria, and we sent all blood films (positive and negative) to Sana'a University for quality control. We measured parasitaemia by counting the number of asexual parasites against at least 200 leucocytes in thick films and used thin films to confirm hyperparasitaemia. To standardise reading of parasite density between Taiz and Hodeidah, technicians in Taiz measured samples with parasitaemia from both sites. Haemoglobin was measured on venous blood using a spectrophotometer subject to regular calibration. We used spectrophotometry to measure blood glucose, creatinine, and total serum bilirubin and a portable lactate analyser to measure lactate in whole fresh venous blood.

Data were double entered into EPI Info 6.04 and analysed by using Stata 8. To test the difference in means, we used the Student's $t$ test if data were distributed normally and the KruskalWallis test if not. We used Pearson's $\chi^{2}$ test or Fisher's exact test to analyse differences in proportions and binomial distribution to calculate exact confidence intervals for case fatality. We used unconditional logistic regression to investigate the risk factors for death. Variables that were statistically significant $(P \leq 0.1)$ in univariate analysis (adjusted for age) were considered for multivariate models in order of their significance in univariate analysis. Data from clinical history, clinical examination, and

\section{Definitions of symptoms and signs of severe malaria (presence of asexual parasites always required)}

- Cerebral malaria: unrousable coma (Blantyre coma score $\leq 2$ ); persistent, generalised convulsions for at least one hour with hypoglycaemia and other causes of coma excluded clinically. If the child had received a sedative or anticonvulsant drug before admission, the coma score was assessed at one hour and six hours after the drug was given

- Severe malarial anaemia: haemoglobin $<50 \mathrm{~g}$ /litre

- Respiratory distress: presence of indrawing of the bony structure in the lower chest wall, abnormally deep breathing, and grunting; chest radiography was conducted if indicated clinically

- Prostration: inability to sit unassisted in a child who can normally do so, or inability to drink in a child who cannot normally sit up

- Hypoglycaemia: blood glucose $<2.2 \mathrm{mmol} /$ litre in a venous blood sample

- Abnormal bleeding: bleeding from gums, nose, gastrointestinal tract, or venepuncture site

- Hyperparasitaemia: peripheral parasitaemia of $\geq 20 \%$

- Severe renal impairment: plasma creatinine concentration $>264 \mu \mathrm{mol} /$ litre

- Hyperlactataemia: plasma lactate $>5 \mathrm{mmol} /$ litre

- Jaundice: serum total bilirubin $\geq 50 \mu \mathrm{mol} /$ litre

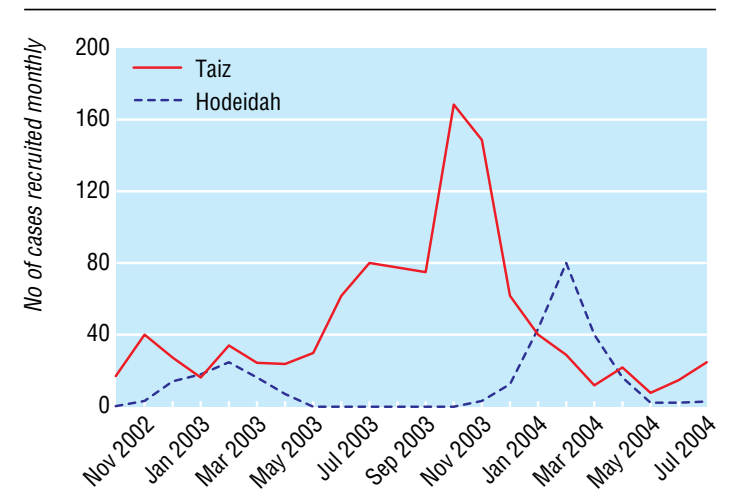

Fig 1 Numbers of confirmed paediatric cases of malaria at two sites in Yemen. Study started mid-November 2002, so admissions for this month represent only 10 days of study

laboratory tests were added sequentially to the model. We used the likelihood ratio test to compare different models.

\section{Results}

Our study ran from 19 November 2002 to 30 August 2004. During this period, 8068 children aged 6 months to 10 years were admitted to hospital in Taiz; 1358 (17\%), mostly from rural areas, were admitted for suspected severe malaria. In Hodeidah the total number of admissions was 4233; 713 (17\%) were admitted with suspected severe malaria. The parents of 11 children in Taiz and four in Hodeidah refused consent for their child to be included in our study. The proportion of admissions for presumed malaria followed the transmission season and varied considerably over the year. In Taiz the proportion ranged from $7 \%$ in February and May to 38\% in November and December, whereas in Hodeidah it ranged from 1\% between July and September to $40 \%$ in February and March (fig 1). Malaria was confirmed microscopically in 1049 children (77\%) in Taiz and in $283(40 \%)$ in Hodeidah. Six hundred and four of the cases in Taiz and 204 in Hodeidah satisfied WHO criteria for severe malaria. By definition, all children were infected by $P$ falciparum. Two children in Taiz and one in Hodeidah were coinfected with $P$ vivuax. One child in Hodeidah with severe anaemia and nephrotic syndrome was also infected with $P$ malariae. Table 1 shows the characteristics of children who met WHO criteria for severe malaria.

Table 1 Characteristics of children who satisfied WHO criteria for severe malaria in two sites in Yemen. Values are number (percentage) unless stated otherwise

\begin{tabular}{lcc} 
& \multicolumn{2}{c}{ Study site } \\
\cline { 2 - 3 } Characteristic & Taiz $(\mathbf{n}=\mathbf{6 0 4})$ & Hodeidah $(\mathbf{n}=\mathbf{2 0 4})$ \\
\hline Sex: & $364(60)$ & $120(59)$ \\
\hline Male & $240(40)$ & $84(41)$ \\
\hline Female & $81(13)$ & $22(11)$ \\
\hline Age (years): & $341(57)$ & $102(50)$ \\
\hline$<1$ & $182(30)$ & $30(39)$ \\
\hline $1-4$ & $2.8(1.42-5)$ & $147(72)$ \\
\hline $5-10$ & & $28(14)$ \\
\hline Median age (interquartile range) & $508(84)$ & $29(14)$ \\
\hline Area of residence: & $46(8)$ & $54 / 63(86)$ \\
\hline Rural & $50(8)$ & \\
\hline Urban & $149 / 206(72)$ \\
\hline Semi-urban & & \\
\hline Breast feeding if child $<2$ years* & & \\
\hline
\end{tabular}

*One case missing in Taiz. 
Table 2 Clinical features on presentation of children with WHO defined severe malaria in two sites in Yemen. Values are numbers of children (percentage) unless stated otherwise

\begin{tabular}{|c|c|c|}
\hline \multirow{2}{*}{ Clinical presentation } & \multicolumn{2}{|c|}{ Study site } \\
\hline & Taiz & Hodeidah \\
\hline \multicolumn{3}{|l|}{ Severe malarial anaemia } \\
\hline All ages ${ }^{*}$ & $221 / 604 \quad(37)$ & $70 / 196(36)$ \\
\hline$<1$ year old & $39 / 81 \quad(48)$ & $16 / 22(73)$ \\
\hline $1-4$ years old & $143 / 341$ (42) & $39 / 98(40)$ \\
\hline $5-10$ years old & $39 / 182(21)$ & $15 / 76(20)$ \\
\hline \multicolumn{3}{|l|}{ Cerebral malaria } \\
\hline All ages & $42 / 604(7)$ & 18/204 (9) \\
\hline$<1$ year old & $1 / 81$ (1) & $1 / 22(5)$ \\
\hline $1-4$ years old & $26 / 341$ (8) & $9 / 102(9)$ \\
\hline $5-10$ years old & $15 / 182(8)$ & $8 / 80(10)$ \\
\hline \multicolumn{3}{|l|}{ Respiratory distress } \\
\hline All ages & $239 / 604(40)$ & $83 / 204(41)$ \\
\hline$<1$ year old & $26 / 81 \quad(32)$ & $9 / 22(41)$ \\
\hline 1-4 years old & $118 / 341(35)$ & $40 / 102(39)$ \\
\hline $5-10$ years old & $95 / 182(52)$ & $34 / 80(43)$ \\
\hline \multicolumn{3}{|l|}{ Prostration† } \\
\hline All ages & $233 / 562(42)$ & $91 / 186(49)$ \\
\hline$<1$ year old & $36 / 80(45)$ & $13 / 21 \quad(62)$ \\
\hline $1-4$ years old & $130 / 315(41)$ & $47 / 93 \quad(51)$ \\
\hline $5-10$ years old & $67 / 167(40)$ & $31 / 72(43)$ \\
\hline Hypoglycaemiał & $51 / 601$ (9) & $15 / 190(8)$ \\
\hline Multiple convulsions & $86 / 604(14)$ & 19/204 (9) \\
\hline Impaired consciousness & $31 / 604$ (5) & $21 / 204(10)$ \\
\hline Jaundice§ & $6 / 600(1)$ & $14 / 182(8)$ \\
\hline Bleeding & $15 / 604(3)$ & $2 / 200(1)$ \\
\hline Hyperparasitaemiaq & $116 / 601$ (19) & $35 / 200(18)$ \\
\hline Geometric mean (SD) parasite count & $19845(6.9)$ & $6973(9.8)$ \\
\hline
\end{tabular}

Table 2 shows the features at presentation of children with WHO defined severe malaria at the two sites. Severe anaemia with haemoglobin lower than $50 \mathrm{~g}$ /litre was a common presentation at both sites: 37\% (221/604) in Taiz and 36\% (70/196) in Hodeidah $(\mathrm{P}=0.8)$ and more than half of children had a haemoglobin value of $<60 \mathrm{~g}$ /litre at both sites. Mean haemoglobin concentrations were 61 (standard deviation 21) and 59 (21) $\mathrm{g}$ /litre at the two sites $(\mathrm{P}=0.25)$. Young age was strongly associated with presentation with severe anaemia $\left(\chi^{2}\right.$ for trend $\mathrm{P}<0.001)$. Severely anaemic children had a median age of 2.0 (interquartile range 1.1-3.5) years, whereas those who were not anaemic had a median age of $3.5(1.75-6)$ years $(\mathrm{P}<0.001)$.

Only $42(7 \%)$ cases in Taiz and $18(9 \%)$ in Hodeidah satisfied WHO criteria for cerebral malaria (Blantyre coma score $\leq 2$ ). Children with cerebral malaria were older than children with severe anaemia (median age 3.3 (1.6-5.3) v 2 (1.1-3.5) years). Respiratory distress was seen in about $40 \%$ of cases at both sites (table 2). Only five patients with respiratory distress had radiological evidence of chest infection. Figure 2 shows the distribution of clinical presentation by age.

Twenty six children died in hospital-21 in Taiz and five in Hodeidah. Two more children died in Taiz immediately after discharge. The in-hospital case fatality rate was 3.2\% (95\% confidence interval $2.1 \%$ to $4.7 \%$ ). The age of children who died was similar to those who survived, but mortality was significantly higher in girls than boys $(5.2 \% v 1.9 \%$; odds ratio $3.0,1.3$ to 6.9 ; table 3). Figure 3 shows mortality rates by presenting syndrome (anaemia, neurological symptoms, and respiratory distress). Most

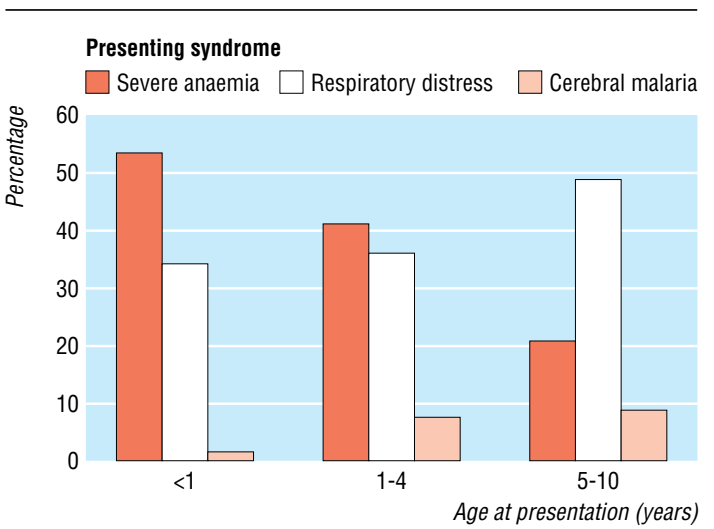

Fig 2 Presentation of children with severe malaria in Yemen by age

deaths were in children with neurological features at presentation. No deaths occurred in children with severe anaemia alone, and the mortality rate in children presenting with respiratory distress alone was lower than 2\%. A strong association existed between respiratory distress and hyperlactataemia, and eight of the 10 children with respiratory distress who died had hyperlactataemia. Four factors were associated independently with mortality in logistic regression: Blantyre coma scale $\leq 2$, history of coma, female sex, and hyperlactataemia (table 4). All children who died had severe malaria according to the revised WHO criteria, although two would have been missed by using the previous WHO case definition. ${ }^{8}$

\section{Discussion}

Although malaria is not usually thought of as a major disease in the Middle East we found that in Yemen, one of the most highly populated countries in the region, severe paediatric malaria is a substantial burden to the health services, both on the coastal plain and in the inland mountains. In the peak malaria season,

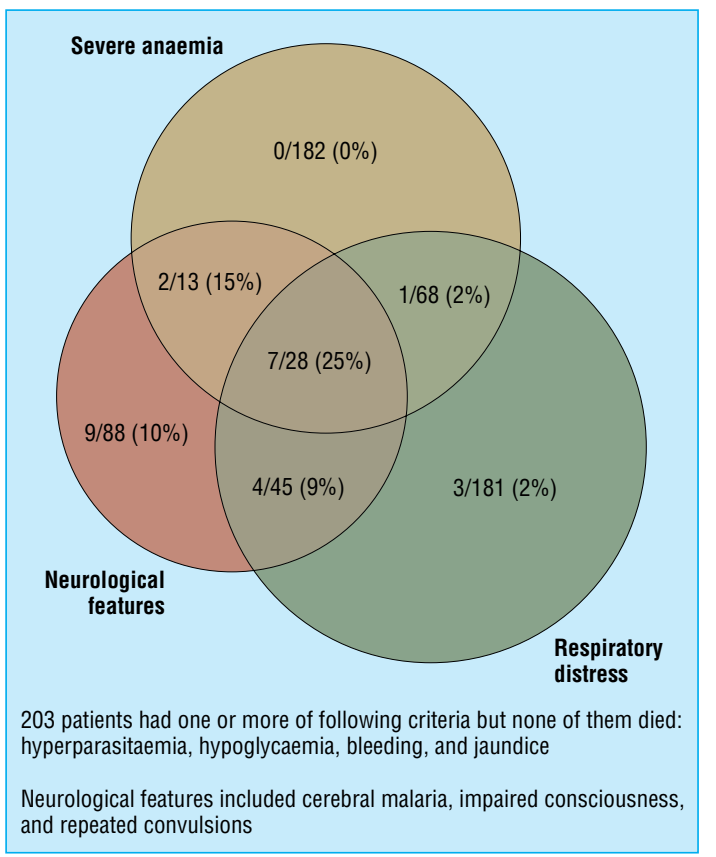

Fig 3 Number of deaths in children with severe malaria by clinical pattern on presentation in two sites in Yemen 
Table 3 Risk factors for case-fatality for malaria in univariate analysis adjusted for age. Values are numbers (percentage) unless stated otherwise

\begin{tabular}{|c|c|c|c|c|}
\hline Variable & Prevalence & Mortality & $\begin{array}{l}\text { Odds ratio } \\
(95 \% \mathrm{Cl})\end{array}$ & $P$ value \\
\hline \multicolumn{5}{|l|}{ Sex } \\
\hline Male & $484 / 808$ (60) & 9/484 (2) & 1 & 0.006 \\
\hline Female & $324 / 808$ (40) & $17 / 324 \quad(5)$ & 3.0 (1.3 to 6.9$)$ & \\
\hline \multicolumn{5}{|l|}{ Clinical history } \\
\hline \multicolumn{5}{|l|}{ No of reported fits: } \\
\hline$<2$ & 674/808 (83) & 12/674 (2) & 1 & \\
\hline$\geq 2$ & $134 / 808$ (17) & $14 / 134(10)$ & $6.3(2.8$ to 14.1$)$ & $<0.001$ \\
\hline Reported history of coma & 167/808 (21) & 21/167 (13) & 18.9 (6.6 to 54.2$)$ & $<0.001$ \\
\hline \multicolumn{5}{|l|}{ Clinical examination } \\
\hline $\begin{array}{l}\text { Abnormal respiratory } \\
\text { rhythm }\end{array}$ & 76/808 (9) & $11 / 76$ (15) & 8.3 (3.5 to 19.5$)$ & $<0.001$ \\
\hline \multicolumn{5}{|l|}{ Respiratory grunting: } \\
\hline No grunting & 747/808 (93) & 19/747 (3) & & \\
\hline Every breath & $61 / 808$ (8) & $7 / 61 \quad(12)$ & 5.2 (2.1 to 13.2) & $<0.001$ \\
\hline Jaundice & 106/808 (13) & $7 / 106(7)$ & 2.5 (1.03 to 6.2$)$ & 0.03 \\
\hline \multicolumn{5}{|l|}{ Dehydration*: } \\
\hline None & 579/808 (72) & 15/579 (3) & 1 & 0.05 \\
\hline Some & 178/808 (22) & $7 / 178$ (4) & 1.53 (0.6 to 3.9$)$ & \\
\hline Severe & $51 / 808$ (6) & 4/51 (8) & 3.2 (1.02 to 10.3$)$ & \\
\hline Cold periphery & $148 / 808$ (18) & 9/148 (6) & 2.4 (1.04 to 5.5) & 0.03 \\
\hline Prostration without CM & $324 / 808$ (40) & $7 / 324(2)$ & 4.6 (0.88 to 46.2$)$ & 0.05 \\
\hline \multicolumn{5}{|l|}{ Blantyre coma score: } \\
\hline$>4$ (normal) & $686 / 808(85)$ & 7/686 (1) & 1 & \multirow{3}{*}{$<0.001$} \\
\hline $3-4$ & $61 / 808$ (8) & 2/61 (3) & $3.3(0.7$ to 16.5$)$ & \\
\hline$\leq 2 \dagger$ & $61 / 808$ (8) & 17/61 (28) & 39 (13.5 to 115.3) & \\
\hline Witnessed fitting & $50 / 808$ (6) & $10 / 50(20)$ & $11.3(4.7$ to 27.0$)$ & $<0.001$ \\
\hline Posturing & 20/808 (3) & $8 / 20(40)$ & 27.6 (9.4 to 81.2 ) & $<0.001$ \\
\hline Abnormal pupil size & 21/808 (3) & 9/21 (43) & $\begin{array}{c}33.6 \\
\text { (11.2 to 100.6) }\end{array}$ & $<0.001$ \\
\hline Abnormal pupil reaction & 22/808 (3) & $8 / 22(36)$ & 23.8 (8.2 to 69.0$)$ & $<0.001$ \\
\hline Abnormal doll's eye & 13/808 (2) & $7 / 13$ (54) & $\begin{array}{c}51.3 \\
\text { (13.4 to 196.1) }\end{array}$ & $<0.001$ \\
\hline
\end{tabular}

\section{Laboratory data}

Creatinine:

\begin{tabular}{|c|c|c|c|c|}
\hline$<88 \mu \mathrm{mol} / \mathrm{l}$ & 722/789 (92) & $18 / 722$ (3) & 1 & \\
\hline$\geq 88 \mu \mathrm{mol} / \mathrm{l}$ & 67/789 (94) & $8 / 67 \quad(12)$ & 5.7 (2.3 to 14.2) & $<0.001$ \\
\hline \multicolumn{5}{|c|}{ White blood cell count: } \\
\hline$<10000 \times 10^{9} / /$ & $519 / 807$ (64) & $11 / 519$ (2) & 1 & \\
\hline$\geq 10000 \times 10^{9} / /$ & $288 / 807 \quad(36)$ & $15 / 288 \quad(5)$ & 2.6 (1.2 to 5.8$)$ & 0.01 \\
\hline \multicolumn{5}{|l|}{ Lactate: } \\
\hline$\leq 5 \mathrm{mmol} / \mathrm{l}$ & $340 / 460(74)$ & $5 / 340(2)$ & 1 & \\
\hline$>5 \mathrm{mmol} / \mathrm{l}$ & $120 / 460(26)$ & $11 / 120(9)$ & 6.9 (2.2 to 21.0$)$ & $<0.001$ \\
\hline \multicolumn{5}{|l|}{ Bilirubinł: } \\
\hline$<50 \mu \mathrm{mol} / \mathrm{l}$ & $762 / 782$ (97) & $25 / 762(3)$ & 1 & \\
\hline$\geq 50 \mu \mathrm{mol} / \mathrm{l}$ & $20 / 782(3)$ & $1 / 20(5)$ & $1.5(0.2$ to 11.8$)$ & 0.7 \\
\hline
\end{tabular}

${ }^{*} \chi^{2}$ test for trend $(P<0.05)$

tIn one patient the score changed from 2 to 3 after giving $50 \%$ dextrose.

$\Varangle B i l i r u b i n$ results missing for four cases in Taiz and 22 in Hodeidah.

around $40 \%$ of paediatric admissions were for clinically diagnosed malaria, and more than half of the cases satisfied the current WHO criteria for severe falciparum malaria. This proportion of admissions is comparable to many sites in Africa during the peak season, so malaria prevention should be a public health priority in Yemen. In the absence of reliable data on entomological inoculation rates, asymptomatic carriage of parasites in children, and the incidence of adult malaria we cannot exclude the possibility that a few children carried parasites asymptomatically (that is, the finding of parasites was incidental to their presentation).

Variations in the presentation and outcome of severe malaria in children depend on the epidemiological setting and the healthcare setting. ${ }^{910}$ Although the clinical pattern of paediatric malaria in Yemen was similar to that seen in Africa, we found some important differences-particularly in terms of syndromes associated with poor clinical outcome-which have implications for clinical practice. More than half of the children with WHO defined severe malaria in both sites were anaemic (haemoglobin $<60 \mathrm{~g}$ /litre). Severe anaemia (haemoglobin $<50 \mathrm{~g}$ /litre) was associated with young age, whereas the peak for cerebral malaria was at a later age; this pattern is similar to that found in many African sites. ${ }^{11-13}$ Transmission is probably lower in Yemen than in most of Africa and adults do not seem to acquire appreciable immunity to malaria; this supports the view that age and not immunity is the key determinant of this difference. About $40 \%$ of patients at each site had respiratory distress, and no significant difference in the age of these patients was seen between the two sites; this is a higher proportion than is found in northern Ghana $(23 \%),{ }^{11}$ southern Tanzania $(11 \%),{ }^{12}$ Kenya $(13 \%),{ }^{14}$ Mozambique $(27 \%),{ }^{15}$ and Gabon $(31 \%) .{ }^{16}$ Chloroquine was first line treatment for non-severe disease at the time of our study and this may have contributed to the high proportion of children with severe anaemia - sentinel site data from Yemen and studies from neighbouring countries suggest that chloroquine has up to a $50 \%$ parasitological failure rate within 14 days.

None of the children in our study with severe anaemia but no other signs of severity died; indirect evidence suggests that when blood is readily available this form of severe malaria seldom causes death. ${ }^{9-11}{ }^{14-16}$ Blood is readily available in Yemen, and in the absence of clear guidelines on when it should be given (in Yemen and elsewhere ${ }^{17}$ ) clinicians have a low threshold for transfusion. In contrast to some studies in Africa, however, where respiratory distress without neurological signs is a strong predictor of mortality, ${ }^{14}{ }^{18}$ almost all deaths in our study were in children with cerebral malaria or other neurological signs at presentation. Several possible reasons exist for this discrepancy. Mild respiratory signs are common in less severe malaria, ${ }^{19}$ and children with respiratory distress in Yemen may be referred for care earlier than in some African settings; in addition blood and fluid resuscitation may be used more widely in Yemen. Study clinicians may interpret the WHO criteria for respiratory distress differently, and although these criteria are thought to be reasonably reproducible, different signs of respiratory distress have different associations with poor prognosis-deep breathing is particularly associated with mortality. ${ }^{20}$ We made considerable effort to train study clinicians and to standardise the method of determining respiratory distress. Thus, we think that differences in clinical measurement are unlikely to explain the whole difference between sites. As in other studies ${ }^{10}$ we found no association between the outcome and the level of parasitaemia-none of the 47 patients with at least $20 \%$ of their red blood cells infected died. This finding questions the importance of parasitaemia as a criterion in the WHO definition of severe paediatric malaria.

One potentially important difference between our study in Yemen and studies in Africa is that female sex was a significant predictor for death in univariate and multivariate analyses, although all measured risk factors were distributed evenly

Table 4 Multiple logistic regression model of factors associated with mortality in children with severe malaria in Yemen

\begin{tabular}{|c|c|c|c|c|}
\hline \multirow[b]{2}{*}{ Variable } & \multicolumn{2}{|c|}{ Without hyperlactataemia } & \multicolumn{2}{|c|}{ With hyperlactataemia } \\
\hline & $\begin{array}{l}\text { Odds ratio } \\
\text { (95\% Cl) }\end{array}$ & $P$ value & $\begin{array}{l}\text { Odds ratio } \\
\text { (95\% CI) }\end{array}$ & $P$ value \\
\hline Female sex & 3.9 (1.5 to 10.4) & 0.006 & 4.6 (1.3 to 16.2$)$ & 0.016 \\
\hline History of coma & 4.3 (1.3 to 14.4$)$ & 0.017 & 8.0 (2.1 to 30.6$)$ & 0.002 \\
\hline Blantyre coma score $\leq 2$ & 16.9 (5.5 to 51.4$)$ & $<0.001$ & 7.2 (1.8 to 28.9$)$ & 0.006 \\
\hline Hyperlactataemia >5 mmol & & & 6.1 (1.8 to 20.2) & 0.003 \\
\hline
\end{tabular}




\section{What is already known on this topic}

Severe anaemia, cerebral malaria, and respiratory distress are associated with poor outcome in paediatric malaria in Africa

Little is known about severe malaria in the Middle East

\section{What this paper adds}

Severe malaria is a common reason for paediatric admissions in Yemen and most deaths are associated with neurological features

Female sex is a risk factor for mortality from malaria in Yemen; reasons for this are not clear

between both sexes. Since this difference has not been found elsewhere it is probably not due to biological differences between the sexes. It could be due to differences in background immunity between male and female children-boys have more contact with the vector for various cultural reasons including the clothing they wear and the time they spend outdoors. Another possible cause is that for cultural reasons boys and girls present at different times; health education is needed if this reflects a delay in the presentation of girls.

Hospital studies are no substitute for epidemiological studies in the community and can underestimate the burden of malaria-they obviously reflect only those children who reach hospital. Our study demonstrates, however, that the burden of malaria in children is considerable in large areas of Yemen. Recording the similarities and differences between severe malaria presenting in the Yemen and in Africa is important for case management, and raises questions about the underlying pathophysiology of the disease. Malaria control should be a priority in Yemen, and lessons could be learnt from other areas of intense but highly seasonal malaria, such as West Africa.

We thank the children and their parents and the staff in Yemeni-Swedish Hospital (Taiz) and Althowra Hospital (Hodeidah). Malcolm Molyneux and Katherine Maitland provided constructive comments.

Funding: The study was funded by UNICEF-UNDP-World Bank-WHO Special Programme for Research and Training in Tropical Diseases (TDR), project A10491. AA-T was supported by TDR grant A30333 and CJMW by the Gates Malaria Partnership, with funding from the Bill and Melinda Gates Foundation.

Contributors: The study was devised and this paper drafted by AA-T, A Assabri, SJ, and CJMW. It was conducted by AA-T, NA-M, and KA, with contributions from all authors. Data were analysed primarily by AA-T, who is guarantor.

Competing interests: None declared.

Ethical approval: Ministry of Public Health and Population, Yemen; Faculty of Medicine and Health Sciences, Sana'a University; and the ethics committee of the London School of Hygiene and Tropical Medicine.

1 Editorial. Time for the renaissance of medicine in the Middle East. Lance 2006;367:959.

2 World Health Organization. World malaria report 2005. Geneva: WHO, 2005.
3 Snow RW, Omumbo JA, Lowe B, Molyneux CS, Obiero JO, Palmer A, et al. Relation between severe malaria morbidity in children and level of Plasmodium falciparum transmission in Africa. Lancet 1997;349:1650-4.

4 Snow RW, Bastos de Azevedo I, Lowe BS, Kabiru EW, Nevill CG, Mwankusye S, et al. Severe childhood malaria in two areas of markedly different falciparum transmission in east Africa. Acta Trop 1994;57:289-300.

5 Slutsker L, Taylor TE, Wirima JJ, Steketee RW. In-hospital morbidity and mortality due to malaria-associated severe anaemia in two areas of Malawi with different patterns of malaria infection. Trans R Soc Trop Med Hyg 1994;88:548-51.

6 Modiano D, Sirima BS, Sawadogo A, Sanou I, Pare J, Konate A, et al. Severe malaria in Burkina Faso: influence of age and transmission level on clinical presentation. Am J Trop Med Hyg 1998;59:539-42.

7 World Health Organization. Severe falciparum malaria. World Health Organization communicable diseases cluster. Trans R Soc Trop Med Hyg 2000;94:S1-90.

8 Imbert P, Gerardin P, Rogier C, Ka AS, Jouvencel P, Brousse V, et al. Severe falciparum malaria in children: a comparative study of 1990 and 2000 WHO criteria for clinical presentation, prognosis and intensive care in Dakar, Senegal. Trans R Soc Trop Med Hyg 2002;96:278-81.

9 Allen SJ, O'Donnell A, Alexander ND, Clegg JB. Severe malaria in children in Papua New Guinea. QJ Med 1996;89:779-88.

10 Taylor T, Olola C, Valim C, Agbenyega T, Kremsner P, Krishna S, et al. Standardized data collection for multi-center clinical studies of severe malaria in African children: establishing the SMAC network. Trans R Soc Trop Med Hyg 2006;100:615-22.

11 Mockenhaupt FP, Ehrhardt S, Burkhardt J, Bosomtwe SY, Laryea S, Anemana SD, et al Manifestation and outcome of severe malaria in children in northern Ghana. Am J Trop Med Hyg 2004;71:167-72.

12 Schellenberg D, Menendez C, Kahigwa E, Font F, Galindo C, Acosta C, et al. African children with malaria in an area of intense Plasmodium falciparum transmission: features on admission to the hospital and risk factors for death. Am J Trop Med Hyg 1999;61:431-8.

13 Imbert P, Sartelet I, Rogier C, Ka S, Baujat G, Candito D. Severe malaria among children in a low seasonal transmission area, Dakar, Senegal: influence of age on clinical presentation. Trans R Soc Trop Med Hyg 1997;91:22-4.

14 Marsh K, Forster D, Waruiru C, Mwangi I, Winstanley M, Marsh V, et al. Indicators of life-threatening malaria in African children. $N$ Engl J Med 1995;332:1399-404.

15 Varandas L, Julien M, Van Lerberghe W, Goncalves L, Ferrinho P. Independent indicators of outcome in severe paediatric malaria: maternal education, acidotic breathing tors of outcome in severe paediatric malaria: maternal education,
and convulsions on admission. Ann Trop Paediatr 2000;20:265-71.

16 Dzeing-Ella A, Nze Obiang PC, Tchoua R, Planche T, Mboza B, Mbounja M, et al. Severe falciparum malaria in Gabonese children: clinical and laboratory features. Malar J 2005;4:1

17 Maitland K, Nadel S, Pollard AJ, Williams TN, Newton CR, Levin M. Management of severe malaria in children: proposed guidelines for the United Kingdom. BMJ 2005;331:337-43.

18 English M, Waruiru C, Amukoye E, Murphy S, Crawley J, Mwangi I, et al. Deep breathing in children with severe malaria: indicator of metabolic acidosis and poor outcome. Am J Trop Med Hyg 1996;55:521-4.

19 O'Dempsey TJ, McArdle TF, Laurence BE, Lamont AC, Todd JE, Greenwood BM. Overlap in the clinical features of pneumonia and malaria in African children. Trans $R$ Soctap in the clinical features of

20 Newton CR, Valim C, Krishna S, Wypij D, Olola T, Agbenyega T, et al. The prognostic value of measures of acid/base balance in pediatric falciparum malaria, compared with other clinical and laboratory parameters. Clin Infect Dis 2005;41:948-57.

(Accepted 22 August 2006)

doi 10.1136/bmj.38959.368819.BE

bmj.com 2006;333:827

Faculty of Medicine and Health Sciences, Sana’a University, PO Box 13078, Sana’a, Yemen

Abdullah Al-Taiar lecturer

Ali Assabri professor

Molham Al-Habori professor

Ahmed Azazy professor

Department of Infectious and Tropical Diseases, London School of Hygiene and Tropical Medicine, London WC1E 7HT

Shabbar Jaffar reader in statistics

Brian M Greenwood professor

Christopher J M Whitty professor

Yemeni-Swedish Hospital, Taiz, Yemen

Nagiba Al-Mahdi paediatrician

Khaled Ameen paediatrician

Correspondence to: A Al-Taiar a_m_altaiar@yahoo.com 